\title{
El confesionalismo de Felipe II y la Inquisición
}

\author{
JOSE MARTINEZ MILLAN \\ Universidad Autónoma de Madrid
}

\section{LOS ORIGENES MEDIEVALES DE LA INQUISICION}

\section{Inquisición episcopal e Inquisición monástica}

La palabra Inquisitio tiene su origen en el procedimiento establecido por el papado a finales del siglo XII o principios del siglo XIII. En 1184, en verona, hallándose presente el emperador Federico Barbarroja, el pontífice Lucio III imponía a los obispos la obligación de proceder a unas visitas de inspección anual por sus diócesis y procurar que en el transcurso de las mismas los fieles denunciasen a los herejes. Todo ello, más explicitado, quedó reflejado en la bula Ad Abolendam que posteriormente pasó a las Decretales de Gregorio IX. Este fue el origen de la Inquisición. Pocos años después, ante los graves problemas que la cruzada contra los albigentes planteaba al papa Inocencio III, el concilio de Letrán establecía la legitimidad de las investigaciones pastorales, la investigación de oficio, las confiscaciones, el confiar al reo al brazo secular y, por último, el animadversio debita (condena a la hoguera); de manera que, en 1215, el proceso per inquisitionem era ya un hecho consumado.

Con todo, buena parte de los historiadores consideran a Gregorio IX (12271241) el fundador de la Inquisición, ya que, en el concilio de Tolosa (1229) estableció un tribunal extraordinario formado por jueces delegados de forma permanente, encargados de perseguir y juzgar a los herejes: los inquisidores apostólicos. Es decir, se trataba de un "cuerpo de especialistas" (dependientes directamente de la Sede Apostólica, y, por consiguiente, con jurisdicción superior a la de los Ordinarios) que iban de diócesis en diócesis solucionando los problemas de herejía locales, ante la llamada de sus gobernantes u obedeciendo mandatos de otras instancias. Tales personajes eran extraídos de la orden de Santo Domingo. La razón de ello consistió en que los dominicos eran ante todo predicadores. Su predicación iba destinada a aclarar a los fieles acerca de los peligros de la herejía e, indirectamente, ello suponía también una amenaza. La predicación tiende naturalmente a la Inquisición. En 1231, Gregorio IX introducía además en las Decretales una serie de medidas que caracterizaron la actuación del Santo Oficio, tales como, privar a los culpables de herejía de sus derechos y excluirlos del gobierno municipal, prohibir toda discusión entre laicos a propósito de la fe católica o negar sepultura eclesiástica a los cadáveres de los condenados. A par- 
tir de entonces, la Inquisición se fue extendiendo paulatinamente por toda la cristiandad a impulsos del Pontífice, asistida por ordinarios y regulares (1).

La creación de la Inquisición permanente o monástica por parte de Gregorio IX provocó numerosos problemas, ya que, al ser confiada la persecución de la herejía a un juez delegado del papa (el inquisidor), muchos canonistas interpretaron que la jurisdicción de esta nueva Inquisición suspendía a la de los obispos (Inquisición episcopal), dado que en estricto derecho canónico, la jurisdicción del juez delegado del papa prevalecía sobre la del juez ordinario. Para solucionar este malentendido, Inocencio IV extendía la bula Ad extirpanda (1252) en la que confirmaba la competencia que tenían los ovispos - al igual que la Inquisición- en materia de fe. Posteriormente, Bonifacio VIII consagró esta fórmula precisando que los dos jueces, obispo e inquisidor, podían ejercitar su jurisdicción communiter vel divisim contra los herejes. No obstante, estas disposiciones pronto se manifestaron insuficientes y defectuosas porque, por una parte, no se coordinaba la acción de ambos jueces y -a veces- resultaba que se juzgaba a un reo dos veces por el mismo delito; por otra parte, tal sistema daba lugar a abusos y parcialidades, dado que las sentencias o castigos impuestos por obispos e inquisidores sobre un mismo caso rara vez coincidian. Para remediar tales problemas, Clemente $V$ modificaba -en el concilio de Viena (1311)- la legislación vigente a través de la Multorum querella. Este documento fijaba la nueva reglamentación en el proceder de las autoridades eclesiásticas: ordinario e inquisidor debían actuar conjuntamente en la fase más delicada del proceso. Ambos podían independientemente citar e inquirir sobre un reo, pero debían actuar de conjunto cuando se trataba de pronunciar la sentencia del proceso. Publicada en 1317 por Juan XXII junto a los otros decretos del concilio de Viena, la Multomum querella permaneció en vigor durante todo el período que estuvo vigente la Inquisición (2).

\section{La Inquisición medieval en los Reinos Hispanos}

La instauración de la Inquisición durante la Edad Media en los reinos hispanos peninsulares siguió caminos muy dispares: mientras en la Corona de Castilla solamente existió a través de la actividad de los ordinarios (Inquisición episcopal), como se muestra en la persecución a Enrique de Villena o en el proceso a Pedro Martínez de Osma, en la Corona de Aragón se llegó a imponer la Inquisición monástica o de los dominicos en común acuerdo con los ordinarios merced a los esfuerzos de Raimundo de Peñafort, quien, en el concilio de Tarragona de 1243, consiguió aprobar un reglamento o "manual" de Inquisición. Inspirándose en aquellas reglas, la asamblea definió además qué clase de personas eran los que debian ser perseguidos, garantizó la inmunidad a los culpables que se confesaban en período de gracia, abandonó a los obstinados al brazo secular y propuso fórmulas de condena o absolución según los casos. Solamente restaba -lo que se consiguió al poco tiempo- asegurarse la primacia sobre la jurisdicción de los ordinarios (3).

(1) Henri Maisonneuve, Enudes sur les onigines de l'Inquisition, París, 1960, cap. 5‥

(2) Agostino BORROMEO, "Contributo allo studio dell' Inquisitione e dei suoi rapporti con el potere episcopale nell' Italia Spagnola de Cinquecento". Annuario dell' Istituto Storico Italiano per l' etáa Moderna e Contemporanea 29-30 (1977-1978) 221-223.

(3) Juan A. LLORENTE, Historia Crítica de la Inquisición en España. Madrid, 1980, I, caps. 3 y $4^{\circ}$. 


\section{Fundación de la "Inquisición española"}

El 1 de noviembre de 1478 , Sixto IV expedía una bula en la que concedía a los Reyes Católicos el privilegio perpetuo de nombrar como inquisidores a personas honradas en sus reinos. Tales facultades permitieron a los monarcas designar personas de su confianza que comenzaron a ejercer el oficio inquisitorial en el arzobispado de Sevilla, a partir de 1480 , al margen de los ordinarios: Tal actuación resultaba anormal y anticanónica, pues disentía de la forma acordada en el concilio de Viena, por to que -en 1482- el pontífice se veía obligado a extender una serie de nuevas bulas en orden a precisar el alcance de los privilegios concedidos en la de 1478.

En primer lugar, tras alegar ciertas confusiones de la bula fundacional y de consultar con distintos cardenales, Sixto IV ordenaba que los nuevos inquisidores actuaran en común acuerdo con los ordinarios, al mismo tiempo que negaba extender' a los monarcas el privilegio concedido en 1478 para la Corona de Aragón dado que allí ya existía Inquisición. Para demostrar que la autoridad máxima sobre la institución residía en la Santa Sede, el pontífice nombró a siete inquisidores para los reinos de Castilla y León. Finalmente, se recordaba a los monarcas que todo reo estaba en su derecho de apelar a Roma cuando no estuviera de acuerdo con su sentencia y que los ordinarios tenían poder para absolver y reconciliar a herejes al margen del Santo Oficio'(4).

La reacción de Fernando el Católico no' se hizo esperar y sus presiones diplomáticas dieron su fruto: al año siguiente (1483) el papa extendía una nueva bula ratificando los privilegios concedidos en la de 1478, si bien, también dejaba muy claramente establecida la jurisdicción apostólica del Santo Oficio al exigir que los nuevos inquisidores actuasen conjuntamente con los ordinarios y al mantener un juez de apelaciones que dependiera directamente de Roma. Con todo, los Reyes Católicos no se resignaron a dejar fuera de su influencia tal institución $\mathrm{y}$, durante los últimos años del siglo XV, desplegaron una frenética actividad diplomática con el fin de influir en la jurisdicción eclesiástica de la institución: En 1486 conseguían que el pontífice nombrase a Tomás de Torquemada Inquisidor General para las Coronas de Castilla y Aragón, siendo los monarcas quienes proponían el candidato para tan alto cargo. Ello resultaba especialmente importante, toda vez que la jurisdicción del Inquisidor General era delegada directamente del papa, y, por consiguiente, era superior a la de los obispos u ordinaria. Al año siguiente, Inocencio VIII consentía en la pretensión de los Reyes, según la cual, el cargo de juez de apelaciones recaía en la misma persona del Inquisidor General, lo que significaba que cualquier discrepancia suscitada entre los nuevos inquisidores y los ordinarios, o cualquier apelación de los reos debía ser resuelta por el

(4) Sobre el tema, Fidel FITA', "Nuevas fuentes para escribir la historia de los judíos españoles". Boletin de la Real Academia Española 15 (1889) 313-346; 442-491; 561-598. Bernardino LLORCA, Bulario Pontificio sobre la Inquisición española. Roma 1949. Tarsicio AZCONA, Isabel la Católica. Madrid 1964, cap. 60. Juan MESEGUER, "La etapa fundacional (1480-1517)". Historia de la Inquisición en España y América. 'Madrid, 1984, I, 281-400, dirigida por J. Pérez Villanueva y B. Escandell. 
propio Inquisidor General (5). Finalmente, el pontífice admitía que el único camino para reinsertarse en la ortodoxia religiosa y social en los reinos hispanos era a través de la Inquisición, por lo que daba facultad a dicha institución de perseguir y juzgar a todos los sospechosos de herejía aunque éstos hubieran abjurado sinceramente de sus errores y estuvieran absueltos por su confesor.

No considero pertinente explicar más profundamente la evolución jurisdiccional y administrativa del Santo Oficio hispano y sus derivaciones en el ámbito político y eclesiástico (6). Solamente quiero recordar que, desde el punto de vista de su actuación, todos los historiadores se muestran de acuerdo en afirmar que tan temida institución fue establecida en Castilla para perseguir a los judeoconversos. El motivo de esta persecución, según los textos legales, fue netamente religioso: descubrir y castigar todos aquellos judíos que no se habían convertido sinceramente al cristianismo. Ahora bien, muy pronto se demostró que la actuación inquisitorial también se movía por otros motivos: políticos, sociales y económicos. Ello ha suscitado una amplia discusión entre los historiadores actuales en torno a las verdaderas causas por las que se instauró este organismo en Castilla y, consecuentemente, por el concepto que se tenía de judeoconverso. Todo parece indicar que, además de motivos religiosos, la Inquisición fue utilizada para suplantar unos grupos de poder (que dominaban la administración central de la monarquía y los gobiernos municipales) por otros (7).

Con todo, la persecución contra los judeoconversos comenzó a disminuir apenas transcurrieron las primeras décadas del Siglo XVI (8), lo que llevó a que amplios sectores sociales se planteasen la razón de la existencia de la institución. Es cierto que, tras la revuelta de las Comunidades, el Santo Oficio orientó su actividad primordialmente en atajar la expansión del luteranismo y en controlar la lectura de las obras de Erasmo en Castilla (9); sin embargo, la falta de definición ideológica de la Monarquía produjo que la Inquisición sobreviviera sin tener una finalidad precisa, lo que no se consiguió hasta el reinado de Felipe II.

\section{LA POLITICA CONFESIONAL DE LA MONARQUIA HISPANA}

En 1555, Felipe II había pasado desde Inglaterra a Flandes para recibir de manos de su padre las coronas de los diferentes reinos que le dejaba en herencia.

(5) Solamente se admitía instancia a Roma cuando el reo era un Obispo, Bernardino LLORCA, pp. 139 y 184 .

(6) Al respecto, véase: Francisco TOMAS Y VALIENTE, Gobierno e instituciones en la España del Antiguo Régimen. Madrid 1982, cap. 1ํ. Roberto LOPEZ VELA, "Estructuras administrativas del Santo Oficio". Historia de la Inquisición en España y América. Madrid, 1993, II, 63-136. Dirigida por J. Pérez Villanueva y B. Escandell.

(7) Francisco MARQUEZ VILLANUEVA, Investigaciones sobre Juan Alvarez Gato. Madrid, 1960, cap. 3․ ID., "Conversos y cargos concejiles en el siglo XV". Revista de Archivos, Bibliotecas y Museos. 63 (1957) 503-540. B. NETANYAHU, "Motivos o pretextos? La razón de la Inquisición". Inquisición española y mentalidad inquisitorial. Barcelona, 1984, dirigido por A. Alcalá.

(8) Véase la cuantificación de las causas en el tribunal de Toledo, J.P. DEDIEU, "Les causes de foi de l' Inquisition de Tolede (1483-1820)". Melanges de la Casa de Velazquez 14 (1978) 143-170.

(9) Agustín REDONDO, "Luther et l' Espagne de 1520 à 1536". Melanges de la Casa de Velazquez I (1965) 109-165. Marcel BATAILLON, Erasmo y España. México 1966, caps. 5ำ yo. 
Dos años después, llamaba a Carranza -que se encontraba en Londres ocupado en la conversión de los ingleses- para que estuviera junto a él y le pusiera al día de la situación religiosa de Flandes. Durante el tiempo que el flamante monarca estuvo ausente de Bruselas, ocupado en la guerra contra Francia, Carranza se percató del grave problema religioso que existía en aquellos territorios. El decano de la universidad de Lovaina, Ruardo Tapper, le había informado de las corrientes heréticas propugnadas por estudiantes hispanos que, desde hacía pocos años, habían surgido en dicha universidad aprovechando su ausencia por estar ocupado en el concilio de Trento y el flojo castigo que se les había impuesto a sus seguidores. Así mismo, le comunicó el ininternumpido comercio de libros heréticos que traían desde Alemania y la conexión que existía con los herejes descubiertos en Sevilla por aquellas fechas. Ante tan alarmante situación, Felipe II, una vez acabada la guerra contra Francia, ordenó que se hicieran mayores diligencias para descubrir toda la trama. Dado que su vuelta a Castilla era inminente, dejó a fieles peones que le informaran puntualmente de la evolución religiosa de estos territorios. Pero, por si todo ello fuera poco, unos meses antes de su partida, llegaron a sus oídos rumores de la heterodoxia del Catecismo que había publicado (en 1557) Fray Bartolomé Carranza, su gran amigo, a quien él había elegido como arzobispo de Toledo, así como del surgimiento de focos luteranos en Sevilla y Valladolid (10).

Una vez en la península, a finales del mismo año (1559), convocaba Cortes, que se reunieron al año siguiente en Toledo, donde además de recibir a su nueva esposa' (Isabel de Valois), se juraba como heredero al príncipe Carlos y se acordaban las primeras medidas contra los moriscos de Granada. Acabadas éstas, y "juzgando incapaz la habitación de Toledo", estableció su Corte, de manera permanente, en la villa de Madrid y'desde ella comenzó a gobernar de acuerdo con todas las ideas e inquietudes que había traído de Europa, procurando evitar la expansión de las ideas religiosas reformistas.

Hasta no hace muchos años, los historiadores encerraban dentro del término "Reforma" los clásicos hechos de ruptura de la cristiandad, surgimiento de Lutero, lucha de la conciencia, etc. No obstante, en la actualidad, los historiadores alemanes han replanteado el significado de estos términos referidos a dicha época, proponiendo nuevos temas que en apariencia poco tienen que ver con el concepto tradicional de "Reforma", tales como la construcción del "estado" o la estructuración que resultó de la sociedad. Estos estudiosos han sostenido que la evolución de la reforma y de la contra-reforma no fueron muy distintas; para ello han comparado fenómenos históricos de ambos movimientos, demostrando que, estructuralmente, se desarrollaron y contribuyeron de manera similar a la transformación de la Europa Central de la edad Moderna (11).

Este desafio a la visión tradicional de la "Reforma" ha venido desde diferentes posturas complementarias: Ya en la década de 1960, Gerhard Oestreich introducía el concepto de "social disciplining" para describir los cambios que se habí-

(10) J. I. TELLECHEA IDIGORAS, "Bartolomé Carranza en Flandes. El clima religioso en los Países Bajos (1557-1558)", Reformata Reformanda. Münster Westfalen 1965, II, 317-343.

(11) Sobre el concepto de confesionalización, véase: Heinrich LUTZ, Reforma y Contrarreforma. Madrid 1992, pp. 116-122 y la bibliografia que sobre el tema se cita al final del libro. 
an producido en la sociedad alemana de la edad Moderna, señalando que la imposición de la disciplina eclesiástica y la consolidación de la identidad confesional influyeron decisivamente en el desarrollo político y en el pensamiento filosófico de la época. Un segundo impulso vino de parte de los historiadores que se dedican a la investigación sobre la reforma católica. Ernest W. Zeeden empleó el término "la formación de confesiones" (Konfessionsbildung) para denotar las evoluciones paralelas de las reformas luterana, calvinista y católica. En sus investigaciones, Zeeden insistía en la similitud de la evolución de las tres confesiones, que desarrollaron sistemas coherentes de dotrina, de ritos, de personal y de instituciones (12). No obstante, ha sido en los últimos años, cuando historiadores como Heinz Schilling y Wolfgang Reinhard han asumido los conceptos creados por las corrientes anteriores para fundar un nuevo concepto: "confesionalización" (Konfessionalisierung). Con ello, pretenden subrayar el proceso de cambios que envolvió las estructuras de la religión, política, cultura y sociedad de la edad moderna alemana. En un interesante y sugestivo artículo, W. Reinhard formuló los tres principios que caracterizaron la confesionalización: a) La "Reforma" y la "Contra-reforma" tuvieron estructuras paralelas; b) La confesionalización creó grupos sociales de acuerdo a una variedad de pensamientos, incluyendo la formulación del dogma, propaganda confesional, educación, disciplina, rituales y lenguaje; c) la confesionalización reforzó la centralización política cuando las monarquías de la edad Moderna utilizaron la religión para consolidar sus límites territoriales, incorporando la iglesia dentro de su burocracia e imponiendo un control social sobre sus súbditos (13). Por su parte, $\mathrm{H}$. Schilling ha desarrollado este último punto añadiendo que la confesionalización repercutió en la construcción del denominado "Estado Moderno" en tres aspectos: a) en la administración burocrática y en la formación de nuevas instituciones; b) en el ensanchamiento del campo de actividades del Estado (educación, fiscalidad, familia, etc.) y c) en la nueva posición de los gobernantes, de las dinastías y de las Cortes, ya que la alianza entre las iglesias confesionales y el "estado" de ptincipios de la edad Moderna ayudó a poner a cierta distancia el gobernante del súbdito y a elevar al "príncipe" por encima de la sociedad (14).

De acuerdo con estas concisas características, por confesionalización se debe entender -a mi juicio- la formación de las instituciones e ideologías religiosas en

(12) Al respecto, véase la colección de artículos de Ennest Walter ZEEDEN, Konfessionsbildung. Stuttgart 1985. Una definición de dicho concepto, realizada por el propio autor, en Die Entstecbung der Konfessionen. Munchen-Wien 1965, p. 7. Muy clarificador, con bibliografia completa sobre el tema, resulta el trabajo de Peter Thaddäus LANG, "Konfessionsbildung als Forschungsfeld". Historisches Jabrbuch 100 (1980) 479-493.

(13) Wolfgang REINHARD, "Zwang zur Konfessiuonalisierung?. Prolegomena zu einer Theorie des konfessionellen Zeittalters", Zeitschrift für Hisioniche Forschung 10 (1983) 257-277. El mismo volvió sobre el tema: "Gegenreformation als Modernisierung?. Prolegomena zu einer Theorie des konfessionellen Zeitalters" Arcbiv für Reformationsgescbicbte 67 (1977) 226-252. La formulación más sistemática de la confesionalización hecha por Heinz SCHILLING, se encuentra en "Die konfessionalisierung im Reich. Religiöser und gesellschaftlicher Wandel in Deutschland zwischen 1555 und 1620". Historiscbe Zeitscbrift 246 (1988) 1-45.

(14) Heinz SCHILLING, "The Reformation and the Rise of the Early Modern State". Luther and the Modern State in Gernany. Kirksville 1986, pp. 25-26 (ed. James D. Tracy). 
el luteranismo, calvinismo y catolicismo: Ello conllevó la articulación de los sistemas de creencias, el recrudecimiento de los distintos cuerpos clericales, la constitución y desarrollo de las instituciones de cada iglesia con sus distintos ritos; pero también, la confesionalización se refiere al proceso por el cual se consolidaron las estructuras de las Monarquías de la edad Moderna, la imposición de la disciplina social y la formación de las iglesias confesionales que transformaron la sociedad. En mi opinión, tales características, no solamente se dieron en Centroeuropa y en el Imperio, sino también expresan con claridad las directrices políticas que siguió Felipe II. Ellas fueron las que contribuyeron a configurar la imagen del reinado y de la personalidad del Rey Prudente con la que ha entrado en la Historia, imponiendo un halo clerical y católico a la historia de la Monarquía hispana que la ha distinguido de sus semejantes europeas durante los siglos posteriores.

\section{El confesionalismo de Felipe II}

Para no incurrir en la contradicción de estar defendiendo unos ideales religiosos que no eran compartidos plenamente por Roma, como sucediera con Paulo IV y, asimismo, para mantener alejados sus reinos de toda ideología herética o heterodoxa que levantase algún movimiento social, Felipe II inició una amplia reforma: Desde: el punto de vista ideológico y religioso, la monarquía se esforzó por imponer un intransigente sistemas de ideas y creencias a toda la sociedad, utilizando el Santo Oficio como institución que sancionaba a los transgresores. Ello provocó duros enfrentamientos con el Papado, que no se resignaba a perder ni un ápice de jurisdicción e influencia en cuestiones religiosas dentro de la Monarquía Hispana. Desde el punto de vista político, impuso una fuerte centralización en su Monarquía; ello lo consiguió, más que por una reforma o creación de nuevas instituciones, mediante un equipo de servidores ("relaciones personales") que tomaron la defensa del regalismo monárquico con más celo y entusiasmo que el propio rey, siendo el coordinador de todos ellos el cardenal Diego de Espinosa.

Diego de Espinosa nació en Martín Muñoz de las Posadas (Avila) en 1512. Fue hijo de Diego de Espinosa y Catalina de Arévalo, matrimonio de hidalgos, que, además del personaje objeto de estudio, tuvieron a Pedro de Espinosa, Hernando de Espinosa y a Catalina de Arévalo (15). En torno a 1540, comenzó a estudiar en la universidad de Salamanca, en donde estudió derecho, siendo admitido en el colegio mayor de Cuenca en 1543 . Una vez que obturo la licenciatura én derecho, el 27 de junio de 1547 , salió del colegio para ponerse al servicio de Hernando Niño, obispo de Sigüenza (1546-1552) y Patriarca de Indias, como provisor de su diócesis. La muerte prematura de su protector le obligó a dejar el obispado de Sigüenza y volver a su pueblo de donde lo sacó, en 1553, Hernán Pérez de la Fuente, nombrándole oidor de la audiencia de Sevilla. Pérez de la Fuente había sido enviado a visitar dicha audiencia en 1551, donde realizó una reforma aumentando el número de oidores que había en ella con el fin de que hubiera dos salas.

(15) José Luis ORELLA Y UNZUE, "El Cardenal Diego de Espinosa, consejero de Felipe II, el monasterio de Aránzazu y la peste de Pamplona en 1566", Principe de Viana 36 (1975) 566. 
Con este motivo hubo necesidad de letrados, causa por la que fue llamado. Durante su estancia en Sevilla entabló estrecha amistad con el licenciado Vázquez de Alderete y sus servidores, Juan de Ovando y el jovencísimo Mateo Vázquez, todos fieles colaboradores de Fernando de Valdés en la ciudad hispalense, así como con Gaspar Cervantes de Gaete, provisor del arzobispado; todos ellos en grupo minoritario, defendían la posición de Valdés, partidario de la intransigencia religiosa, frente a la mayoría de los canónigos, partidarios de la ideología erasmista, pues habían sido elegidos y nombrados por el arzobispo Alonso Manrique.

En Sevilla permaneció hasta 1556, fecha en la que fue nombrado regente del consejo de Navarra. Allí comenzó a experimentar las medidas adoptadas por el monarca para establecer su ortodoxia religiosa e ideológica: el 20 de noviembre de 1559, Felipe II enviaba una cédula al consejo de Navarra para que vigilase que "ningún natural destros nuestros reinos saliese a estudiar fuera dellos", haciendo especial hincapié en que vigilasen las salidas por los puertos, al mismo tiempo que comenzaban las primeras reformas en las órdenes religiosas.

El nombramiento de Diego de Espinosa como presidente del Consejo de Castilla $y$, posteriormente, de Inquisidor General resulta dificil de explicar. Los mismos coetáneos vieron con sorpresa tan rápido y alto encumbramniento en una persona tal y los historiadores actuales no se explican su vertiginoso ascenso, atribuyéndolo a su pertenencia al "partido ebolista", cuyos miembros dominaban la mayor parte de las instituciones de la Monarquía cuando nuestro personaje fue llamado a la Corte (16). No obstante, si nos atenemos a este criterio (de "partidos") para explicar la evolución política de Espinosa, no se debe olvidar que los personajes con quienes mantuvo más estrecha amistad durante la etapa en que ocupò distintos cargos por el Reino fue con los seguidores de Fernando de Valdés y, así mismo, su ascenso contrasta con la pérdida de influencia que simultáneamente experimentaba el "partido ebolista" ante el Rey. No son las únicas contradicciones que se observan en la evolucón personal de Espinosa. Al poco tiempo de residir en la Corte, solicitaba ser ordenado presbítero, siendo así que ocho años antes era recomendado por $H$. Niño para ocupar un cargo en cualquier organismo de la Monarquía, pero "no quería ser clérigo" (17). En mi opinión, tales contradicciones estuvieron en relación con el confesionalismo que implantó Felipe II, poniendo la religión al servicio de la política, de lo que fue consciente Espinosa, al menos, desde su estancia en Navarra.

\section{DIEGO DE ESPINOSA Y LA IMPLANTACION DEL CONFESIONALISMO}

Como ya se ha dicho, la reforma confesionalista que impuso Felipe II tras su vuelta a la península requería una administración centralizada y eficaz. Para ello era necesario un gobiemo personal cuyas órdenes fuesen ejecutadas con rapidez. Esta intención llevó a designar a Diego de Espinosa, "hombre nuevo", como presi-

(16) Para W.S. MALTBY, El Gran Duque de Alba. Un siglo de España y Europa, 1507-1582. Madrid, 1985, p. 99, no hay duda de que Espinosa fue un apadrinado de Exaso. Sobre el "partido ebolista" véase mi trabajo en Instituciones y elites de poder en la Monarquía Hispana durante el siglo XVI. Madrid 1992.

(17) AGS. E, leg. 13, nº 171. 
dente del Consejo de Castilla, saltándose los cauces ordinarios del nombramiento. La forma de despachar con el rey resultaba completamente nueva incluso para los de la Cámara, como testimonia la breve y tajante misiva que Espinosa envió a Francisco de Menchaca, del consejo y cámara real, el 13 de agosto de 1566: "La orden que otras veces se a tenido en lo de las consultas que v.m. dice yo no la sé; mas sé la que su magestad me manda que tenga y ésta se guardará, y en lo que yo pudiere seruir a v.m., ya sabe que se a de hacer" (18). Esta plena confianza real le permitió llevar a cabo las fuertes medidas que suponía la confesionalización.

\section{La implantación del confesionalismo en la administración}

A los pocos días de ser nombrado presidente, redactaba un memorial en el que detallaba minuciosamente las directrices que iba a seguir en el nuevo cargo. Los consejos "debían de gobernar" (19); para ello, ordenaba reglamentar las actividades de cada organismo en sus respectivos libros-registro, designando con claridad cada una de las funciones que se le encomendaban a los distintos oficiales, al tiempo que vigilaban su cumplimiento. Ello daría por resultado un gobierno ágil y ejecutivo (20). Así mismo, insistía en el deber de hacer justicia rápida y bien, para lo que era necesario elegir muy cuidadosamente quién la debía impartir (21).

(18) BL. Add. 28704, fol. $14 \mathrm{r}$.

(19) "La ley del ordenamiento manda que los del consejo se guarden de los decires ymportará mucho que V. $\mathrm{S}^{\mathrm{a}}$. nos mande abstener de pláticas extraordinarias que suelen ocupar mucho y porque para aprouechar el tiempo aprouechará mucho también el número de las personás, será cossa sustancial que V. $S^{ \pm}$. dé orden como los que son del consejo de la cámara o de la guerra o de la hacienda o cruzada vayan al $\mathrm{q}^{2}$ los días y oras que solían yr y al menos a las mañanas en ninguna manera ni para ningún negocio algan fuera rrepartiendo los otros extraordinarios negocios por las tareas de la semana y aun si fuere posible por las tardes que no ay consejo Real, que son Martes, Jueves y Sábados, porque ymportaría ansímismo que las otras tardes en que se despachan muy muchos negocios se hallassen presentes, pues, se halla el presidente y la ordenança que todos los del q⿳a lo estén y ellos no muestran particular exemción por donde no la guarden" (IVDJ, envío 72 , parte $3^{\circ}$, fols. $9 \mathrm{r}-11 \mathrm{v}$ ).

(20) "Como V. Sa. Illma tiene entendido, los negocios que ay son muchos más de los que se pueden despachar en las oras ordinarias del q⿳a y por esso, una de las principales cosas en $q$ V. $S^{\underline{a}}$. podrá serurir a nro señor y a su mag. será en estar siempre muy sobre el auiso a que de esse poco tiempo q ay no se pierda nada, y para esto ynportará guardar la ordenaça en lo de hazaer los escriuanos porque embaraçan mucho que no se hagan sino los quatro meses que la ordenança manda, y aun aquellos meses, mandar que se hagan a las tardes o antes de las ocho o después de las once, si se hizieren a la mañana" (IVDf, env. 72).

(21) "Sobretodo a de estar V. So . aduertido quel presidente del consejo es gouernador y justicia maior destos reinos y ansí, no solamente a de tener cuydado de que se administre con facilidad en el $q^{\circ}$, pero en'las chancillerías y en todos los demás officios de justicia dellos y para esto, procurar siempre quel número de presidentee oydores estén llenos y no hagan ausencias, pues tanta sobra ay de negocios y tanta falta de juezes para despachallos, aunq estén todos proueídos y procurar que su mag no los ocupe en negocios extraordinarios fuera de su audiencia y procurar que aya allí tales personas, nombrando a su mag., ansí para las presidencias como para todos los otros officios, ansí de las audiencias como de todos los otros consejos desta corte questubieren vacos; y para las visitas destos Reynos y para los corregimientos sin ruegos ni rrespectos de nadie, tales personas quales conuengan al servicio de nro señor y de su mag." (IVDJ, env. 72). 
El rígido cumplimiento de las obligaciones administrativas sólo podía conseguirse a través de la confianza personal en el comportamiento de determinados oficiales, lo que dió lugar al establecimiento de una cohesionada red de patronazgo. Donde primero se experimentó este proceso fue en materia de hacienda. Al poco tiempo de residir en la Corte, Espinosa comenzó a intervenir en tales asuntos (22), teniendo un conocimiento exacto de la situación desde muy pronto. En consecuencia, Espinosa comenzó a meter a sus hombres de confianza, desplazando al "partido ebolista", que venía dominando esta materia. La caída del omnipotente secretario, Francisco de Eraso, permitió esta mutación. La visita que le iniciara su enemigo político, el regente Figueroa, fue continuada por el propio Espinosa a pesar de las muestras de amistad que éste le mostró. El desplazamiento de Eraso de los asuntos de hacienda dejó un gran hueco de poder que fue ocupado por distintos partidarios del nuevo patrón, algunos de ellos, antiguos servidores del gran secretario: la secretaría de finanzas fue escindida en dos, concediendo las titularidades a Francisco de Garnica y a Pedro del Hoyo, respectivamente; en la lugartenencia de la Contaduría Mayor, que también ocupaba Eraso, fue designado Francisco de Laguna. Pero no fueron estos los únicos cambios; en 1566, Juan de Escobedo fue nombrado secretario del consejo de Hacienda, mientras que Francisco Gutiérez de Cuéllar fue introducido como consejero en el mismo organismo junto con Francisco Hernández de Liévana, Juan de Ovando y Juan Delgado. A partir de esta fecha, Espinosa no dejó de, al menos, participar en la hacienda real hasta su muerte, como se evidencia en las reformas que realizó en orden a evitar nuevas suspensiones de pagos y a ahorrar gastos de la administración central y casa real.

Junto al Consejo de Hacienda, otros dos, relacionados indirectamente con dicha materia, el de Indias y el de Cruzada, pasaron a ser dominados por clientes de Espinosa. En el de Indias ya se encontraban Gómez Zapata, Hernández de Liévana y Tello Sandoval, a los que vinieron a unirse, Francisco Villafañe, Miguel Ruiz de Otalora, Ovando, Gamboa, todos clientes de Espinosa. Por lo que resprecta al Consejo de Cruzada, Bernardo de Fresneda fue nombrado Comisario General. En el Consejo de Castilla, Espinosa realizó un cambio radical introduciendo, en el mismo año de su nombramiento como presidente, diversos personajes de su confianza, antiguos condiscípulos suyos: LIévana, Zapata, etc., a los que añadió Padilla, Quiroga, Redín, Villafañe y otros, que estaban en el Consejo de Indias. Pero donde más patentes quedan las reformas confesionalistas y su relación con la administración fue en la elección que se hizo de que los miembros pertenecientes al santo Oficio ocupasen los cargos de la Monarquía de mayor responsabilidad; baste recordar que Francisco de Menchaca, Rodrigo de Castro, Gaspar de Quiroga, Juan de Ovando, Hernando de Vega, Framcisco Soto Salazar y Busto de Villegas, fueron consejeros de Inquisición con Espinosa. Con todo, en los Consejos de Estado y Guerra, la influencia de Espinosa parece que fue muy pequeña a pesar de que participó en ellos. La política con otros reinos de la Monarquía, fuera de la península, solamente la pudo realizar a través de personajes concretos: el Duque

(22) La labor de Espinosa dirigiendo la Hacienda de Castilla desde 1566 es ciutada por A.W. LOVETT, Philip II and Mateo Vazquez de Leca. The Government of Spain, 1572-1592. Gèneve 1977. ID., "Juan de Ovando and the Council of Finance". Historical Journal 15 (1972) 1-21. 
de Alba para Flandes; los hermanos Luis de Requesens y Juan de Zúñiga para los territorios italianos y más concretamente con Roma.

Ahora bien, dominar la Corte, no era todo; para gobernar también era necesario controlar el Reino. En una nota que Mateo Vazquez enviaba al rey, hacía referencia a un libro, que perteneció al cardenal en vida, en el que había apuntado los nombres de todos sus apadrinados para ocupar cargos en la administración de la Monarquía (23). Dicho manuscrito, junto a otros muchos papeles de Espinosa, pasaron a poder de Mateo Vázquez, convirtiéndose -de alguna manera- en el nuevo patrón de la red clientelar que había tejido el prelado, hasta el punto de que buena parte de los nombramientos posteriores para cargos en los organismos de la Monarquía, se extrajeron de esta fuente. Esta lista no constituía una reserva anárquica de la que se extraían los personajes aleatoriamente para los cargos, sino que los nombramientos obedecían a claros y racionales criterios expresados por el propio Espinosa en carta de Mateo Vázquez:

"y creo que regla general lo sería buena, reduzir estas prouisiones de officios a dos estados de gentes, como son collegiales para los de letras y regidores para los que se uubiesen de encomendar a cauallieros de capa y espada, haziendo memoria de los que serían a propósito, de que el presidente se podría y devría con particular studio y secreto ynformar de consejeros y de otras personas graues de sciençia y consciencia y sin pasión; y los prelados y corregidores son los mejores testigos para los regidores, y la exepción desta regla general se podría praticar en las personas muy notables que uuiesse. Y si para yntelligencia particular de V. Mg. fuesse seruido de mandar scriuir (como ya otra vez se hizo) a los presidentes y regentes de las audiencias, prelados y otras personas señaladas que auisasen con sumo secreto a $\mathrm{V} . \mathrm{Mg}$. de las personas que les ocurriesen para yglesias y los demás officios, podría ser couneniente diligencia $y, V . M g$. hazer muy açertadas prouisiones y exemplares" (24).

Como se comprueba en esta sucinta relación, el control de los cargos fue algo que Espinosa mantuvo desde el primer momento de llegar a la presidencia de Castilla, utilizando siempre la voluntad real como excusa de su patronazgo.

\section{La implantación del confesionalismo en la sociedad y política}

Pero la formación de una red clientelar no constituyó exclusivamente la implantación del confesionalismo, sino que se complementó con la aplicación de unas medidas religiosas adoptadas por la Monarquía.

\section{a) La reforma de las órdenes religiosas}

Después de haber intentado varias veces que el Pontífice, "tuviesse por bien de mandar que se reformassen todas las casas de frayles y monjas claustrales en

(23) El libro lo publiqué en, "Un curioso manuscrito. El libro de Gobierno del Cardenal Espinosa (1512-1572)". Hispania 53 (1993) 399-444.

(24) IVDJ, envio 51, nº 11. Mateo Vázquez a Felipe II, Madrid a 27 octubre 1572. 
estos nuestros reynos de Castilla y Nauarra, Aragón, Valencia y Cataluña y en todos los otros reynos subjectos y adjacentes a las españas de las órdenes de sanct Agustín y sanct Francisco y sancto Domingo y de todas qualesquier otras órdenes asy de frayles como de monjas, agora sean monacales o mendicantes", el monarca ordenaba taxativamente a su embajador en Roma, Francisco de Vargas, por carta fechada en la ciudad imperial el 13 de marzo de 1561, que procurase de la Santa Sede un breve para la reforma, convencido de que este embajador tomaría el asunto con "más calor y cuydado que sus predecesores" (25).

El despacho real -que, al parecer, había sido preparado por Fr. Bernardo de Fresneda, confesor del rey- urgía la necesidad de la reforma en todas las órdenes al mismo tiempo que expresaba la profunda preocupación de la Corte por la situación religiosa de la época. No obstante, para llevar a cabo la reforma, Felipe II había formado una Junta de doctos que le asesoraban en la materia y que venía actuando, al menos, desde 1562. Tal Junta estaba compuesta por Fray Bernardo de Fresneda, obispo de Cuenca y confesor del Rey; Fernando de Valdés, arzobispo de Sevilla e Inquisidor General; el doctor Velasco, del Consejo de Castilla y de la Cámara Real; ejerciendo de secretario Francisco de Eraso. Sin duda los personajes más influyentes en esta época eran Fresneda y Velasco, dado que los otros dos cayeron pronto en desgracia, siendo sustituidos.

Uno de los principales problemas para la reforma de las órdenes religiosas - a juicio de la Corte de Madrid- lo constituía el hecho de que sus superiores fueran extranjeros y que éstos residieran fuera de los territorios que componían la Monarquía Hispana; por ello, se exigía que la ejecución de la reforma debería ser confiada en cada provincia religiosa a dos vicarios generales o provinciales de los observantes de Castilla. Poco tiempo después se solicitaba que los generales de las órdenes fueran naturales de estos reinos, pues los generales foráneos no sabían adaptarse a la observancia d elos conventos hispanos. Tal solicitud, presentada cuando se reanudaba el Concilio de Trento, no fue del agrado de Roma, que se negó a aceptarla, quejándose el Pontífice a Felipe II, a través del embajador Francisco de Vargas.

A pesar de la negativa del Pontífice, el monarca no se dió por vencido y, como si no se fiara de lo que se estaba acordando en Trento sobre la materia, envió otro memorial, fechado en Monzón el 15 de noviembre de 1563, donde se encontraba por haber reunido Cortes, a su nuevo embajador en Roma, don Luis de Requesens (26). El cambio tan radical de la vida regular que se proponía llevar a cabo el monarca, se desprende del contenido del memorial que acompañaba a la instrucción del propio rey. En este alegato se pedía que el breve que debía extender el Papa concediera autorización para deponer de su cargo a cualquier prelado de los claustrales que se resistiese a la introducción de la observancia en sus conventos. Para extirpar radicalmente la vida claustral, el breve debía de prohibir, bajo pena de excomunión, la admisión de nuevas candidatas a los monasterios claustrales. Los muchos monasterios pequeños

(25) Para todo este apartado, Otger STEGGINK, La Reforma del Carmelo español. Roma 1965.

(26) AGS. E., leg. 902, $\mathrm{n}^{\circ} 48$. El texto ha sido publicado según la copia que se encuentra en el Archivo Zabálburu, en el libro : Pío IV y Felipe II. Primeros diez meses de la embajada de don Luis de Requesens en Roma, 1563-1564. Madrid 1891, pp. 70-84. 
deberían ser reorganizados y agrupados en dos o tres de suficiente capacidad. Los bienes de los monasterios claustrales se aplicarian e incorporarían a los de la observancia.

La Corte de Madrid perseguía, por tanto, un breve particular para la reforma de los regulares en España, prescindiendo así de lo que se estaba acordando en el Concilio de Trento sobre la materia. La rapidez con que el Concilio aprobó el decreto sobre la reforma de los regulares no satisfizo a los miembros hispanos del Concilio ni al propio Felipe II, que lo consideraron más un saneamiento de costumbres, ajustándolas a las leyes de cada orden, más que una reforma. No obstante, las pretensiones del monarca no se llevaron a cabo y ello, no tanto por oposición del Pontífice, según comentaba Luis de Requesens a Felipe II, cuando por la mediación del cardenal Borromeo, pues el punto básico de la reforma propuesta por el Rey Católico, a saber, la reducción total de los claustrales a la observancia, no había sido aprobado en el Concilio de Trento.

Las negociaciones de la reforma entraron a partir de entonces en el torbellino de los enredos políticos que parecía no tener fin, hasta el punto que, durante el último año del pontificado de Pío IV, la tirantez entre Madrid y Roma se había llegado a la ruptura diplomática. A ello contribuyó, no sólo los problemas de jurisdicción y reforma de órdenes religiosas, sino también la intromisión del Consejo Real en la celebración de los concilios provinciales ordenada por Felipe II en julio de 1565. Solo la elección de Miguel Ghislieri (Pío V), dominico e inquisidor, ferviente partidario de la reforma eclesiástica, llevó nuevas esperanzas al entendimiento.

Aprovechando la nueva relación favorable con el Pontífice, Felipe II volvió a insistir para que se proveyese en cuanto a las "otras órdenes en que no hay distinción de claustrales y observantes", señalando concretamente una serie de órdenes. Dos meses después de que Felipe II hiciera esta petición a su embajador en Roma, Pío V extendía una serie de breves titulados, In prioribus, en los que se daba facultad a los obispos y provinciales para subdelegar, procurando así agilizar la reforma; también disponía en cuanto a las reformas de las órdenes que no tenían observantes. Remataba esta colección legislativa el breve Superioribus mensibus (fechado en Roma el 16 de abril de 1567), "auténtico código -en opinión de García Oro- de la reforma de las órdenes religiosas" (27).

Ahora bien, si en Roma se habían producido grandes novedades desde que por primera vez Felipe II intentase obtener el breve para realizar las reformas de las órdenes religiosas y no fue hasta el nombramiento de Pío $\mathrm{V}$ cuando cambiaron las relaciones entre la Monarquía Católica y el Pontífice, en la Corte de Madrid también se habian producido grandes cambios por estas fechas. Desde 1566, la Junta que se ocupaba de la reforma religiosa estaba compuesta por: Diego de Espinosa, Presidente del Consejo de Castilla e Inquisidor General; el licenciado Menchaca, del Consejo y Cámara Real; Francisco Pacheco, fraile franciscano, confesor de la reina y predicador en la Corte; sirviendo como secretario Gabriel de Zayas.

(27) José GARCIA ORO, "La reforma de las órdenes religiosas en los siglos XV y XVI". Historia de la Iglesia en España. III-1‥ La Iglesia en la España de los Siglos XV y XVI. Madrid, 1980, pp. 211-361, dirigida por R. García Villoslada. 
Tras recibir el breve, Espinosa -que dirigía la Junta- redactó un memorial en el que se daba instrucciones para llevarlo a cabo al mismo tiempo que llamaba a los provinciales de las distintas órdenes religiosas para que la Junta les instruyera en su cometido. Durante todo el año 1567 se desató una furia de reformas en todos los reinos de la Monarquía con el fin de acabar con el conventualismo. El 18 de abril, Felipe II ordenaba, como medida previa para las reformas de los conventuales franciscanos que se realizara un inventario de los bienes de los monasterios, lo que provocó el descontento en los religiosos afectados. Todo ello era confirmado por el nuncio Castagna, que se mostraba partidario de establecer solamente los acuerdos de Trento sin llegar a las particularidades que el Pontífice había concedido a Felipe II en el breve Superioribus mensibus.

Los primeros en manifestar sus quejas fueron los franciscanos de la tercera regla, los cuales, antes de que el Pontífice extendiera el breve, ya habían preparado un ambiente hostil. Pero donde, Felipe II encontró una cerrada oposición a sus ideas de la reforma fue en la orden de los premonstratenses. La idea de reducir dicha orden dentro de los Jerónimos fue rechazada enérgicamente por sus componentes que se opusieron a su integración, al mismo tiempo que enviaron con toda presteza a fray Gonzalo de Salas a Roma para que hablara con el Cardenal Lomellini, protector de la orden de San Norberto (28). La influencia de los cardenales y la situación conflictiva creada en la península, comunicada por el Nuncio a Roma, motivó que Pío $V$ extendiera un nuevo breve, Nuper cum accepissemus, dirigido al muncio de Madrid, en el que declaraba que los premostratenses debían ser reformados según la observancia de su regla y que los jerónimos no tenían ninguna jurisdicción sobre ellos. De nada sirvieron las quejas del monarca, ya que el nuncio Castagna se encargó de presionar al Cardenal Espinosa para que con urgencia se remediasen los agravios que había recibido la citada orden y se le devolviesen todos los bienes que los jerónimos les habían tomado. No sucedió lo mismo con los "isidros", cuya unión se culminó con éxito y se realizó de forma pacífica dado el tronco común de ambas órdenes. Por contra, en la reforma de los cartujos, el Papa se oponía a dar mayor poder a la Junta al considerar "que se le quiere usurpar su jurisdicción en estas cosas".

Todo ello, unido al celo regalista que los obispos hispanos ejercieron en la instauración de la reforma, motivaron que Pío V se mostrase reticente en las gracias que había concedido, poniendo el asunto en manos del cardenal Ormaneto (29). Aunque el embajador Zúñiga tenía una floja opinión de la valía de Ormaneto, éste supo aguantar todas las presiones de la Monarquía Hispana y sacar adelante el plan que el Pontífice pretendía: eliminar a los ordinarios de la reforma de los frailes y encargársela a representantes de los regulares; esto es, lo que Pío V pretendía era nombrar "comisarios apostólicos encargados de la reforma de las órdenes religiosas" (30).

(28) J. GOÑI GAZTAMBIDE, "La reforma de los premonstratenses españoles del siglo XV". Hispania Sacra 13 (1960) 12-14. El trabajo de Goñi resulta fundamental para el tema.

(29) G. CATALANO, Controversie giurisdizionali tra Cbiesa e Statto nell' età di Gregorio XIII e Filippo II. Palermo 1955, pp. 62-65

(30) E. de la MADRE DE DIOS y O. STTEGINK, Sania Teresa y su tiempo. Madrid 1984, II-2, p. 525. 


\section{b) Aplicación de los acuerdos de Trento en la Monarquía}

En diciembre de 1563 concluía el concilio de Trento. Entre los numerosos cánones aprobados en la sesión XXTV, se señalaba la obligación de celebrar un concilio cada tres años en todas las provincias eclesiásticas con el fin de corregir los abusos, costumbres, etc. de los clérigos y fieles. Para iniciar esta serie de concilios provinciales, el de Trento prescribió que durante el año siguiente, el metropolitano de cada provincia eclesiástica y en su defecto el más antiguo de los sufragáneos; lo convocase. Felipe II, que por cédula de 12 de julio de 1564 había aceptado los acuerdos del Concilio tridentino en todos los territorios de su Monarquía, se dispuso a que se cumpliese también este canon. Con tal fin, se entregaba al Consejo de Castilla, en enero de 1565, un formulario para que discutiera la forma cómo se llevarían a cabo, al mismo tiempo que recibía los informes pedidos a tres prelados de sus Reinos invitándoles a realizar tales concilios: los arzobispos de Santiago, Sevilla y Granada, el cardenal de Burgos, los obispos de Oviedo y León que eran exentos y al obispo de Córdoba, que debía presidir el Concilio de Toledo por hallarse preso el arzobispo Carranza en Roma.

Seguidamente, Felipe II nombró a sus representantes en los concilios provinciales (31) -lo que produjo gran disgusto en Roma, que veía en la actitud del rey una intromisión en su jurisdicción- para que le informasen minuciosamente del desarrollo de los mismos. Ello resulta lógico si. se tiene en cuenta que la doctrina tridentina fue adaptada por el rey Prudente al contenido ideológico de su actuación política. Adaptar los acuerdos de Trento a la ideología política de la Monarquía Hispana y llevar a cabo la remodelación de las instituciones con el fin de ponerlas al servicio de esta política, requería personas de gran confianza del monarca, dadas las dificultades que iban a tener en aplicarlos.

En la Corte, fue el doctor Martín de Velasco quien centralizó todos estos asuntos; ayudado por elısecretario Gonzalo Pérez. Ello resultaba lógico teniendo en cuenta que había sido uno de los principales asesores de Felipe II en relación a la actitud que debía tomar frente a los cánones que se discutían durante la tercera etapa del Concilio de Trento, habiendo asistido personalmente a la primera etapa. Fue Velasco quien, con el beneplácito del monarca, convocó los concilios provinciales, quien redactó las instrucciones que debían seguir los representantes reales, lo que se debía discutir en ellos y el procedimiento que se debía seguir. Por su parte, el cardenal Espinosa, no solamente se ocupó de aplicar los acuerdos de Trento, junto al doctor Velasco, en los diversos territorios de la Monarquía, sino también, como obispo de Sigüienza, mostró un celo poco común para implantar tales acuerdos.

(31) Felipe II nombraba a su representante en el concilio de Toledo, Francisco de Toledo, asi como el asesor que, en materias teológicas y de derecho, le debía aconsejar, que fue Francisco Soto Salazar. Por lo que respecta al concilio de Granada, el monarca elegía a don Diego López de Haro, primer marqués del Carpio, como su representante, y a Antonio Covarrubias y. Leyva como asesor, mientras el conde de Monteagudo era designado representante real en el concilio de Salamanca. El 14 de septiembre de 1565 , el conde de Aitona recibía un despacho real, nombrándolo su representante en el concilio provincial que correspondia a la provincia eclesiástica de Tarragona. 


\section{c) La definición de una ideología ortodoxa}

El tercer paso que dio Felipe II fue definir la ideología que justificaba su actuación política y a la que debían sujetarse todos sus súbditos. Este "programa político" ha sido calificado con diferentes términos -no todos igual de precisospor los historiadores posteriores.

la implantación de una ideología ortodoxa comenzó en primer lugar por la visita y reforma de los estudios universitarios. En 1564, era enviado Juan de Ovando como visitador a la universidad de Alcalá. Ovando venía sirviendo a Fernando de Valdés como provisor del arzobispado de Sevilla hasta esta fecha en que aceptó visitar la universidad Complutense, a pesar de la insistencia del Inquisidor General para mantenerlo en la ciudad Hispalense. La universidad de Alcalá se había constituido en uno de los centros académicos con una tendencia religiosa interiorista (recogida) definida desde su fundación frente a la universidad de Salamanca en donde se respiraba una espiritualidad más formalista e intelectual. Ello era debido a la idea que tuvo su fundador, el cardenal Cisneros, de hacer una universidad semejante a la de París, no solamente en la materia que constituía la facultad más importante de la universidad, la de teología, en perjuicio de todas las demás y sobre todo el derecho; lo contrario que sucedía en Salamanca, donde el estudio de ambos derechos (utroque iure) resultaba esencial, sino también en los modos de explicarla, al introducir la vía nominalista (32). No resulta extraño, por tanto, que en torno a Alcalá surgiera una espiritualidad interiorista, difícil de controlar por la autoridad correspondiente, que a veces derivó en corrientes heréticas, como la de los alumbrados (33).

La visita de Juan de Ovando a la universidad de Alcalá se debe encuadrar dentro de este ambiente de fijación de la ortodoxia por parte de la Corona, tratando de controlar los estudios de dicha universidad, siempre mirados con recelo. También obedece a este espíritu la visita que realizó Diego de Covarrubias, en 1567, a la universidad de Salamanca. El mismo proceso se dio en la universidad de Valencia a través de los jesuitas y con el apoyo del Patriarca Ribera (34). Parece que también se llevó a cabo una reforma en la universidad de Granada, impulsada por el arzobispo Guerrero. Aunque, no se dispone de numerosos datos sobre la materia parece que se amplió el número de cátedras y se vigiló con gran cuidado quiénes las ocupaban (35).

Pero la ortodoxia ideólogica y religiosa también se vigiló, al mismo tiempo que se definía de materia negativa, a través de los Catálogos de libros prohibidos. Como sucediera con las reformas anteriores, el monarca pretendía controlarla a través de una institución en la que pudiera influir, tal era la Inquisición. Aunque ya había publicado un catálogo en 1559 , la conciencia que se tenía -según consta al final del

(32) Melquíades ANDRES MARTIN, "Renovación en Teología dogmática y ascética en España (1500-1530)". Antbologica Annua 11 (1963) 129.

(33) Melquiades ANDRES. Los Recogidos. Madrid 1977.

(34) Sebastián GARCIA MARTINEZ, El Patriarca Ribera y la extinpación del erasmismo valenciano. Valencia 1977.

(35) Juan LOPEZ MARTIN, "Don pedro Guerrero como obispo del tiempo de la Contrarreforma". Archivo Teológico Granadino 31 (1968) 216-218. 
mismo- era que había sido realizado de manera apresurada. La publicación del Indice romano de 1564, consecuencia del Concilio de Trento, provocó un período de indecisión en la sociedad, como muestran las numerosas consultas que los diferentes tribunales presentaron sobre el asunto al Consejo de Inquisición, negándose a admitir su validez dentro del ámbito territorial de la Monarquía Hispana. Evidentemente, ello requería la elaboración de un nuevo Catálogo por parte de la Inquisición hispana. El 30 de octubre de 1569, la Suprema escribía una acordada a todos los tribunales dándoles la noticia "...se ha acordado hazer un nuevo cathálogo para en él prohibir y vedar los libros a donde se allaren los dichos errores y falsa doctrina" (36); a los pocos días, el propio Espinosa mandaba una provisión a las universidades en las que se recababa la opinión y colaboración de sus profesores. Las contestaciones de esta consulta fueron centralizadas por el maestro Francisco Sancho, comisario de Salamanca, para que los consultase con los profesores de aquella universidad. A principios de 1572 ya se habían iniciado las tareas en la facultad de Teología y sus maestros habían tomado las primeras resoluciones y acuerdos sobre la elaboración de dicho Indice, si bien, éste no se finalizaría hasta 1583.

\section{d) La enseñanza de la reforma religiosa y control social}

La reforma que llevaba a cabo el monarca no solo consistía en definir la ortodoxia, sino en implantarla en la sociedad. Para ello, se comenzó por reestructurar la distribución y límites de las diócesis que desde tiempos de Fernando III (en el siglo XIII) apenas sí habían experimentado variación (37). A partir de la segunda mitad del siglo XVI, la geografía eclesiástica de la península experimentó una gran transformación: aumentó considerablemente el número de obispados. Aunque en Roma pensaban que el acrecentamiento del número de obispados obedecía a una maniobra de Felipe II para tener más votos en los concilios universales, el esfuerzo principal iba dirigido a centralizar las diócesis en manos de los obispos con el fin de catequizar el mundo rural. Evidentemente, ello suponía que los nuevos prelados debían de conocer y estar comprometidos con la reforma religiosa que llevaba a cabo el monarca; para lo cual nadie cumplía mejor tales requisitos que los prelados que habían asistido a Trento, la mayor parte de ellos habían pasado por el Consejo de Inquisición o habían desempeñado el cargo de inquisidor en algún tribunal del Santo Oficio.

La enseñanza de la nueva ortodoxia religiosa se debía realizar mediante la predicación y la catequesis a los fieles, sobre todo aquellos que vivían en el ámbito rural. Para ello, los nuevos prelados comenzaron por formar intelectual y moralmente al clero, creando seminarios y visitando periódicamente los pueblos de sus diócesis (38), poniendo en práctica los acuerdos tridentinos, al mismo tiempo que,

(36) AHN. Inq., lib. 356, fol. 151r.

(37) Demetrio MANSILLA, "La reorganización eclesiástica española en el siglo XVI". Anthologica Annua 4 (1956) 97-239; 5 (1957) 9-261. ID., "Panorama histórico-geográfico de la Iglesia española en los siglos XV y XV". Historia de la Iglesia en España. III-1 ${ }^{\circ}$. La Iglesia en la España de los siglos XV y XVI. Madrid 1980, pp. 3-24.

(38) Francisco MARTIN "Fundación de los primeros seminarios españoles" Hispania Sacra 16 (1963) 5-24. C. SANCHEZ ALISEDA, "Los seminarios tridentinos". Razón y Fe (1945) 189-201. 
para llevar a cabo la labor catequizadora que propugnaban, los obispos se sirvieron de ciertos miembros, de reconocido prestigio, de órdenes religiosas. A partir de la mitad del siglo XVI aparecen grandes predicadores, como Tomás de Villanueva, fray Luis de Granada, Juan de Avila o Dionisio Vázquez, que sirvieron de modelo a los del barroco y fundaron la oratoria sagrada hispana. Los predicadores del siglo XVI analizaron a fondo su oficio y crearon una serie de retóricas eclesiásticas dirigidas a enseñar y convencer a los fieles (39). Junto a la predicación, el catecismo constituyó el otro gran instrumento para educar al pueblo, como lo demuestra la cantidad de ejemplares que aparecieron durante la época (40).

\section{LA INQUISICION AL SERVICIO DEL CONFESIONALISMO}

La confesionalización de la monarquía no consistió solamente en implantar una serie de normas religiosas y educar al pueblo, esto es, en imponer una cultura de élite sobre una cultura popular, sino también en vigilar cómo la masa social asumía las enseñanzas de la élite. Para ello, el monarca se valió de una institución ya existente, la Inquisición. Los diferentes estudios que existen sobre las relaciones de causas inquisitoriales demuestran claramente que durante la segunda mitad del siglo XVI aumentaron los procesos por proposiciones (afirmaciones de las que se puede presumir herejía, y que, más que otra cosa, reflejaban una deficiente comprensión de la religión católica), lo que evidencia claramente este proceso de aculturación (41).

Pero además, durante la segunda mitad del siglo XVI, el Santo Oficio experimentó una serie de reformas todas ellas tendentes a crear o perfeccionar la organización del distrito inquisitorial, estableciendo una abundante burocracia (comisarios y familiares) por todo el territorio en el que tenía su jurisdicción. Para buena parte de los historiadores, y no dejan de tener razón, toda esta remodelación se hizo a impulsos del monarca; ahora bien, ¿cuales fueron las razones que movió a la Monarquía a potenciar esta institución, sustentada en una jurisdicción delegada del papa? A mi juicio -y en esto coincido con el profesor López Vela- (42) todo

(39) Félix HERRERO GARCIA, Aportación bibliográfica a la oratoria sagrada española. Madrid 1970. Véase un estado de la cuestión en el trabajo de Antonio CAÑ̃ZARES LLOVERA, "La predicación espafiola en el siglo XVI". Repertorio de Historia de las Ciencias Eclesiásticas en España. Salamanca 1977, VI, 188-266.

(40) Sobre el tema, José Ramón GUERRERO, Catecismos españoles del siglo XVI. La obra catequética del Dr. Constantino Ponce de la Fuente. Madrid, 1969, especialmente, caps. $1^{\varrho}$ y $2^{\circ}$. ID., "Catecismos de autores españoles en la primera mitad del siglo XVI (1500-1599)". Repertorio de Historia de las Ciencias Eclesiásticas en España. Salamanca 1977, II, 255-260.

(41) Entre otros, J.P. DEDIEU, "Les causes de foi de l'Inquisition de Tolède (1483-1820)", pp. 148 y 171, J. CONTRERAS, "Estructura de la actividad procesal del Santo Oficio". Historia de la Inquisición en España y América. Madrid 1993, pp. 603-662, dirigida por J. Pérez Villanueva y B. Escandell. G. HENNINGSEN, "La elocuencia de los números: Promesas de las "relaciones de causas" inquisitoriales para la nueva historia social", Inquisición española y mentalidad inquisitorial. Madrid 1984, pp. 207-225.

(42) En este párrafo sigo casi literalmente las ideas de Roberto LOPEZ VELA, "Estructuras administrativas del Santo Oficio". Historia de la Inquisición en España y América, II. Madrid, 1993, pp. 205-210, con las que me siento completamente de acuerdo. 
ello tiene que ver con el "esfuerzo por aumentar el control del territorio y con el de crear una base social agrupada en torno a una jurisdicción que aparecía como garante de estabilidad social y de los principios políticos" sobre los que se estaba construyendo la Monarquía católica.

Tal remodelación se llevó a cabo bajo la dirección del Inquisidor General Diego de Espinosa y para ello también tuvo que contar con fieles colaboradores:

1. Ampliación del número de tribunales y mayor vigilancia territorial. Durante el periodo en que fue Inquisidor General Diego de Espinosa, el Santo Oficio amplió el número de sus organismos ejecutivos, como eran los tribunales. Además de crear dos tribunales en América, se fundó el tribunal de Santiago de Compostela con el fin de vigilar Galicia, hasta entonces integrada en el distrito de la Inquisición de Valladolid, demasiado amplio para ser controlado, sobre todo en una zona de costa al Atlántico, por donde venía la influencia protestante (43). Así mismo, se asentó de manera definitiva el tribunal de Calahorra en la ciudad de Logroño con el fin de vigilar la frontera francesa. Fruto de este auge que cobraba el Atlántico, por donde se extendían los protestantes, y del que fueron conscientes los propios inquisidores, fue el definitivo asentamiento del tribunal de Canarias, por lo que el 28 de enero de 1562, el Consejo de Inquisición solicitaba información de los oficiales que había en las islas sobre las dificultades que preveían para asentar un tribunal independiente del de Sevilla. Pocos años después, en 1567, la Suprema nombraba al licenciado Ortiz de. Funes, primer inquisidor del nuevo tribunal. Fue, sin duda, el inquisidor general Diego de Espinosa quien dio las primeras instrucciones resolviendo los problemas que aparecieron en los inicios de la historia del tribunal (44).

Pero si el control de las costas atlánticas era importante, no lo era menos seguir controlando el Mediterráneo. Se había acabado la rebelión de los moriscos de Granada y aprovechando la afinidad de intenciones con el Papa y la república de Venecia, Felipe II decidió combatir a los musulmanes por mar. Con motivo de ello se fundó un tribunal de la inquisición de la Mar. El primer inquisidor fue Jerónimo Manrique, hechura del cardenal Espinosa (45). La jurisdicción de éste tribunal también se extendió a los ejércitos de tierra.

2! Reforma y adaptación de las estructuras de la Inquisición a las nuevas exigencias de la Monarquía. El mandato de Díego de Espinosa como inquisidor general comenzó con una visita a los tribunales del Santo Oficio de la Corona de Aragón. La visita perseguía tanto o más que un buen funcionamiento, un relevo de personajes en el órgano de poder visitado. La estrecha relación y padrinazgo que los visitadores tenían con respecto al inquisidor general demuestran claramente: esta intención: En 1566, Jerónimo Manrique, inquisidor en Valencia, realizaba la visita al propio tribunal, acusando a su compañero, el inquisidor Miranda,

(43) Las causas por las que se estableció el tribunal en Santiago han sido bien desarrolladas por J. CON'TRERAS, El Santo Oficio de la Inquisición en Galicia (Poder, Sociedad y Cultura). Madrid 1982, pp. 40-61.

(44) AHN. Inq, lib. 576, fols. 235r-v, $277 \mathrm{v}-278 \mathrm{v}$.

(45) AHN. Ing, lib. 356, fol. $207 \mathrm{r}$, lib. 1232, fol. $58 \mathrm{r}$. 
de no centralizar el distrito (46), no resulta extraño, por tanto, que lo desaconsejase "por descargo de mi conciencia", al cardenal Espinosa para realizar la labor de conversión de los moriscos de aquel reino (47). A principios de 1568, el inquisidor Fiego González realizaba una visita al tribunal de Calahorra, si bien parece que la acabó Jerónimo Manrique, una vez que haía concluido la de Valencia y Barcelona, pues, en estas mismas fechas se le ordenaba desde el Consejo que fuera a esta última inquisición para imponer los castigos a los oficiales de acuerdo a lo que había resultado de la visita que había realizado a dicho tribunal (48). Al año siguiente, el inquisidor Quintanilla la realizaba al tribunal de Sicilia (49), mientras otra criatura del cardenal Espinosa, el inquisidor Andrés Santos, realizaba la visita al tribunal de Mallorca (50).

Las visitas fueron acompañadas con una rígida reglamentación de las funciones que se debían seguir en los tribunales. El hecho de que, pocos años antes, Fernando de Valdés, en el declive de su poder, promulgase las instrucciones de 1561, ha motivado que las reformas e instrucciones que envió Espinosa a los diferentes tribunales hayan pasado desapercibidas; sin embargo, sus ordenanzas fueron dirigidas a una mayor centralización y racionalización de la inquisición: en carta acordada de 1569, establecía la clase y número de libros que debían existir en cada tribunal para registrar sus distintas actividades. Así mismo, ordenaba el procedimiento que se debía seguir tanto en las causas de fe (51) como en las "civiles y criminales tocantes a los familiares y offiçiales del Santo Offiçio" (52). El siguiente paso fue la reglamentación de la actuación de los tribunales en materia de hacienda, no solo en la política de inversiones (rentas fijas) que debian seguir, sino sobre todo en la organización de la misma: creación de los contadores de los tribunales (53).

3. La adaptación de la Inquisición a los principios confesionalistas católicos sobre todo repercutió, como queda dicho, en la organización de los distritos de los tribunales, estableciendo una abundante burocracia (familiares), cuyo número fue establecido en las distintas Concordias que, en su mayor parte, se realizaron en 1568 (54). En las Concordias no solo se fijaron el número de familiares que

(46) La primera acusación decía así: "Que auiendo en la dicha inquisición los oficiales necesarios y los que son menester, ha consentido que en todos los lugares del distrito o en los más del aya inquisición formada, conuiene a saber: teniente de inquisidor e teniente de alguacil, teniente de recptor, teniente de notario del secreto..." (AHN, Inq, leg. 1790, exp. 2).

(47) Ibid, leg. 1791, exp. 5, carta personal de Manrique a Espinosa, fechada el 4 de julio de 1567.

(48) AHN. Inq, lib. 325, fol. 68r-v, 169r.

(49) AHJN. Inq, lib. 252, fol. 28v-29r. Inid, lib. 325, fol. 200v-201r y fol. 235r-v, se encuentran los cargos que dicho inquisidor sacaba de los oficiales del tribunal.

(50) AHN. Inq, leg. 1790, exp. 2.

(51) "Demás de los despachos que serán con esta tocantes a la visita que el señor licenciado Soto hizo el año pasado en esa inquisición y en la de Cataluña, han resultado los aduertimientos que serán con ésta, rubricados del secretario Mateo Vázquez. Conuerná que de aquí adelante se guarden en ellas y también la orden en los dos librillos que se os ymbian de la manera del proçessar" (AHN., Inq, lib. 325, fol. 69r).

(52) AHN. Inq, lib. 325, fol. 68v. Acordada al inquisidor Juan de Llano, fechada en Madrid, el 21 de julio 1568.

(53) Véase mi trabajo, "Las bases económicas del Santo Oficio: la hacienda inquisitorial". Historia de la Inquisición en España y América. II. Madrid 1993, pp. 885-905.

(54) Una completa colección de Concordias con todos los tribunales en, AHN. Inq, lib. 1210. 
debían existir en cada distrito, sino que además, se fijaban los privilegios judiciales que la Corona reconocía a los familiares en cada reino, así como otra clase de privilegios y exenciones concedidos por los distintos monarcas anteriores a través de cédulas; condición indispensable para conseguir tal cargo. No existe bula o breve papal que ordenase a la Inquisición imponer semejante práctica; al contrario, la jurisdicción correspondiente a este tipo de procedimientos emanó de la Corona, de esta manera, todo lo que permitía al familiar del Santo oficio conseguir un cierto grado de honor y privilegio dentro de la comunidad de su distrito procedía del rey, no del papa.

La formación de una vasta red de comisarios y familiares que cubrían la total demarcación del distrito suponía la creación de una amplia capa social identificada con los principios políticos y religiosos que constituian el substrato del santo Oficio que, a su vez, lo eran de la Monarquía Católica. De esta manera, la Inquisición, no solo se convirtió en una organización capaz de reprimir la herejía, sino que también reproducía el sistema social y político que defendía, ocupando así un papel predominante en la configuración de la sociedad estamental de la Monarquía. "Es un papel negativo -dice López Vela (55)- mediante la represión, combinado con otro positivo a través de la reproducción del honor y el privilegio que constituyen a la sociedad estamental. Es una doble funcionalidad vertebrada desde la ortodoxia de la Iglesia" y -añado- el confesionalismo católico de la Monarquía hispana como principio de integración o exclusión social. El apoyo que prestó Felipe II al desarrollo de la organización inquisitorial constituye prueba evidente de los principios confesionales que regía la ordenación política y social de la Monarquía; por consiguiente, no resulta extraño que el rey defendiese contra todo género de protestas de las Cortes de los distintos reinos o de sus órganos de justicia los privilegios inquisitoriales. El Inquisidor General Diego de Espinosa parece que captó plenamente estas ideas: En 1567 enviaba al consejero de la Suprema Francisco de Soto Salazazar, persona de toda su confianza, a que visitase las inquisiciones de los reinos de Aragón, Valencia y Cataluña. Las instrucciones que llevaba eran muy precisas y, a través de ellas, se constata las diversas tareas que se le encomendaron: En primer lugar se le ordenaba que fuera "derecho a la ciudad de Valencia", en donde iría a visitar al virrey, con el que debía mantener buena correspondencia (56). Una vez en el tribunal, debía examinar cómo se cumplía lo acordado "en la visita que el año passado de 66 hizo el licenciado Gerónimo Manrique", pasando después a informarse de "las competencias que (hay) entre los inquisidores y justicias reales de aquella ciudad y reino". Finalmente, "entenderá el estado en que está el negocio de los nuevos convertidos de moros de aquel reyno y ver la orden que se deue dar para la execución de lo que aquí se acordó en la congreación que por mandado de su Magestad se hizo en fin del año pasado de 64, conforme a los capítulos e instrucción y asiento que en ello se tomó por ante Gonzalo Pérez....y la instrucción que cerca desto se imbió a la dicha inquisición de Valencia a principio del año $65 \mathrm{y}$

(55) Cf. Roberto LOPEZ VELA, "Las estructuras administrativas del santo Oficio". Historia de la Inquisición..., p. 211. En mi opinión, es quien más claramente ha expuesto este tema, por ello gran parte de sus palabras las hago mías.

(56) AHN. Inq, lib. 254, fol. 370r, art. $1^{\circ}$ y $2^{\circ}$. 
las causas que a auido para que hasta agora no auer executado aquella" (57). Acabados los asuntos a tratar, especificados en la instrucción, debía partir a Cataluña y después a Aragón, no sin antes dar aviso de su partida al Inquisidor General. En estas dos últimas inquisiciones debía seguir el mismo procedimiento que en Valencia, si bien, en las instrucciones respectivas se hacía especial hincapié en que "verá todos los cabos y capítulos que los de aquel principado han dado a su Magestad, assí en las Cortes de Monzón, cono estando su magestad en dicha ciudad" (58). Una vez realizadas estas visitas, se procedió a extender las Concordias de 1568.

(57) Ibid., art. $4^{\circ}, 14^{\circ}$ y $19^{\circ}$ respectivamente.

(58) Las respectivas instrucciones en, Ibid., fol. 371r y ss. 